Article

\title{
Quantity versus Quality in China's South-to-North Water Diversion Project: A System Dynamics Analysis
}

\section{Yu Yang ${ }^{1, *}$, Lei Yin ${ }^{2}$ and Qingzong Zhang ${ }^{2}$}

1 Department of Public Administration, Southeast University, Nanjing 210096, China

2 School of Economics and Management, Southeast University, Nanjing 210096, China; E-Mails: 101011694@seu.edu.cn (L.Y.); 101001820@seu.edu.cn (Q.Z.)

* Author to whom correspondence should be addressed; E-Mail: yangyu.seu@gmail.com; Tel./Fax: +86-25-5209-0922.

Academic Editor: Miklas Scholz

Received: 30 March 2015 / Accepted: 4 May 2015 / Published: 11 May 2015

\begin{abstract}
The South-to-North Water Diversion (SNWD) Project has entered the operational stage. The infrastructure decreases water shortages and promotes economic growth for North China, whereas the environmental effects have yet to be fully examined. In this paper, an analysis of the interaction between water quantity and water quality is conducted using the system dynamics method. In a specific province covering areas that provide and receive water, simulation results for economic and environmental indicators at different levels of transferred water and pollution rates are obtained. Certain conclusions can be drawn from the findings. First, the SNWD Project can provide a sufficient quantity of water for economic growth in receiving regions. Second, an efficient quantity of transferred water exists, which demonstrates the growth limitation for both agriculture and the groundwater funnel. Third, upgrades in water quality can mutually reinforce the quantity effect and greatly promote economic growth. An environmental limitation exists for all economic activities. Therefore, water quantity and water quality are equally crucial in the SNWD Project to provide an opportunity for sustainable development.
\end{abstract}

Keywords: South-to-North Water Diversion (SNWD) Project; system dynamics modeling; water quantity; water quality; growth limitation 


\section{Introduction}

The South-to-North Water Diversion (SNWD) Project (official translation), or the South-to-North Water Transfer Project, is an infrastructure project designed to divert water from flood-prone southern rivers to China's water-poor northern region [1]. According to the project plan, the annual volume of diverted water is 44.8 billion cubic meters. The size is close to the total water volume of China's Yellow River, which is the third longest river in Asia [2]. Although approximately 253 billion Yuan (Chinese currency, 1 Yuan $=0.16$ U.S. dollar) has been invested in its construction [3], from a cost-benefit point of view, the SNWD Project is a feasible choice for North China and the rest of the country [4,5]. A study on water vulnerability and demand-supply balance dynamics indicates that the incremental water supply from the project would help the receiving region keep pace with the development of the entire country [6].

Similarly to other mega-projects in China and worldwide [7,8], however, controversies surrounding the SNWD Project have continuously been debated by numerous stakeholders and researchers [9-11]. Technological, economic, social, ecological and even political disputes are constant [12]. One-third of the provinces in China are included in the project, and over 200 million people would benefit from the water diversion, making the endeavor more than a simple infrastructure project. To ensure that the project better serves households, firms and farmers, among the disputes, the central concern should focus on the basic demands of those affected. Water demands can be interpreted from two perspectives: efficiently tackling the increasing water gap for human water users and effectively meeting drinking and nondrinking water requirements. Finally, a sustainable water management pattern that not only guarantees a sufficient amount of water but also satisfies a certain standard of water quality should be achieved. Thus, a water transfer project should attain water quantity and water quality goals simultaneously, which is the primary focus of this article.

With decades of studies on the planning and construction of the SNWD Project, the amounts of diverted water and related effects have been well addressed [13,14]. Nonetheless, for a project that virtually violates the laws of nature, the indirect effects of the water diversion have yet to be fully discussed. At the pre-construction stage, some scholars and experts took interest in the environmental uncertainties associated with the project $[15,16]$. Moreover, cooperation among regions has been obstructed by the activities of the primary polluters [17]. Some authors have proposed that the ultimate objective of the SNWD Project is to improve the water environment rather than meet the water demand gap [12]. The costs of the SNWD Project include furthering environmental deterioration through rapid rural transition [18]. Evidence from virtual water calculations shows that North China exports over 50 billion $\mathrm{m}^{3}$ of virtual water (amounting to over one-third of the supply) to South China annually. A majority of the virtual water flow occurs in the form of agriculture products, and brings stress for the water-exporting provinces. [19,20]. Thus, diverted high-quality water is critical for the receiving region as well as the supplier, which is the actual receiver of the "water". In December 2014, President $\mathrm{Xi}$ Jinping urged stronger management to protect water quality and conserve water [21]. With the SNWD Project entering the formal operational phase, controversies should be analyzed from a dynamic perspective. In this paper, therefore, we consider the future and investigate the intrinsic link between water quantity and water quality during the upcoming operational stage instead of studying water quantity during the pre-construction and construction stage, as has been done in the existing literature. 
Regarding the dilemma of quantity and quality in the SNWD Project, we must provide answers to certain unanswered questions. Which is comparatively more essential, water quantity or water quality? Would an emphasis on water pollution treatment introduce extra costs and offset growth in certain regions? To gain better knowledge on potential outcomes, the research community has sought to apply mathematical models in the analysis. Typical quantitative decision-making tools and the computable general equilibrium model have been employed [6,22,23]. Using established simulation methods, data output under various conditions have been obtained to provide information for comparison and further policy design. In most previous studies, the two variables, water quantity and water quality, have been treated separately, which is partly a result of the complexity of the economic-social-ecological analytical framework and is also related to the difficulty of the model description. With the goal of systematically characterizing the inherent relationship between water quantity and water quality, this paper utilizes a methodology of system dynamics analysis to investigate the effects and the trends of the SNWD Project and discusses the implications for sustainable development based on the results of the quantity-quality interaction. Furthermore, these findings may contribute to research and policy applications in other similarly marginal environments around the world. The remainder of this paper is structured as follows. We first describe the study area, the modeling method and data sources used. Then, through a well-designed system dynamics model, we analyze the effects of water quantity and quality in various scenarios. The results of the simulation and prediction are then reviewed and further discussed. Finally, we summarize the study and present policy suggestions for sustainable water management.

\section{Methods and Data}

\subsection{Study Area}

The SNWD Project consists of three canal systems, the eastern route, central (or middle) route and western route. As a result of varying biophysical conditions and social-economic characteristics [24], a single study could not cover them all. Among the three routes, the western route, drilling through the Tibetan Plateau to divert water to the Yellow River, is the most ambitious and is still in the planning phase $[25,26]$. Thus, Figure 1 does not accurately depict this route. The central route is a closed system in which the water is pumped through canals, pipes or tunnels (e.g., under the Yellow River), thus offering relatively good water quality able to meet Class II standards. However, the construction of this canal requires the large-scale relocation of 330,000 people in Henan and Hubei Provinces [27], and the potential disruptions are primarily social rather than economic or environmental [28]. Unlike the central route, the eastern route mostly uses an existing channel. The open system passes through the Beijing-Hangzhou Grand Canal, the world's longest man-made river, developed in the 13th century. Thus, the investment in and displacement of the eastern route are far less than those associated with the central route [29]. However, the eastern route endangers the quality of diverted water because it collects a large amount of pollutants and sediment through the industry-heavy areas, including Jiangsu and Shandong Provinces [30].

The comparison suggests that the eastern route is the most appropriate to research. Although water quality is a general issue for all routes, the eastern route faces the most serious emerging risks, particularly because it covers 71 counties (or cities, districts), directly benefiting a population of 100 million people. Furthermore, the eastern coastal region is more advanced in economic growth than the central 
provinces, such as Henan and Hebei. In 2013, Jiangsu and Shandong ranked among the top three nationwide in terms of GDP (gross domestic product), and the per capita GDP of Tianjin has remained the highest in the nation over the last two years [31]. These features make research on water quantity and quality, as well as the economic and environmental consequences of constructing the eastern route, well worth examining. The first stage of the eastern route was completed in December 2013. The route starts in southern Jiangsu Province, the downstream of Yangtze River, then transfers water to northern Jiangsu, Shandong and Tianjin. In other words, Jiangsu Province not only provides water, but receives water as well. Furthermore, Jiangsu is a critical source of polluted water. Its total, wastewater discharge was the nation's second highest in 2013, accounting for approximately $9 \%$ of that of the entire country [31]. Such conditions would naturally spur fear among people in water-receiving cities. Therefore, along the eastern route, Jiangsu is an ideal study area that sufficiently encapsulates the research concerns and content of this paper.

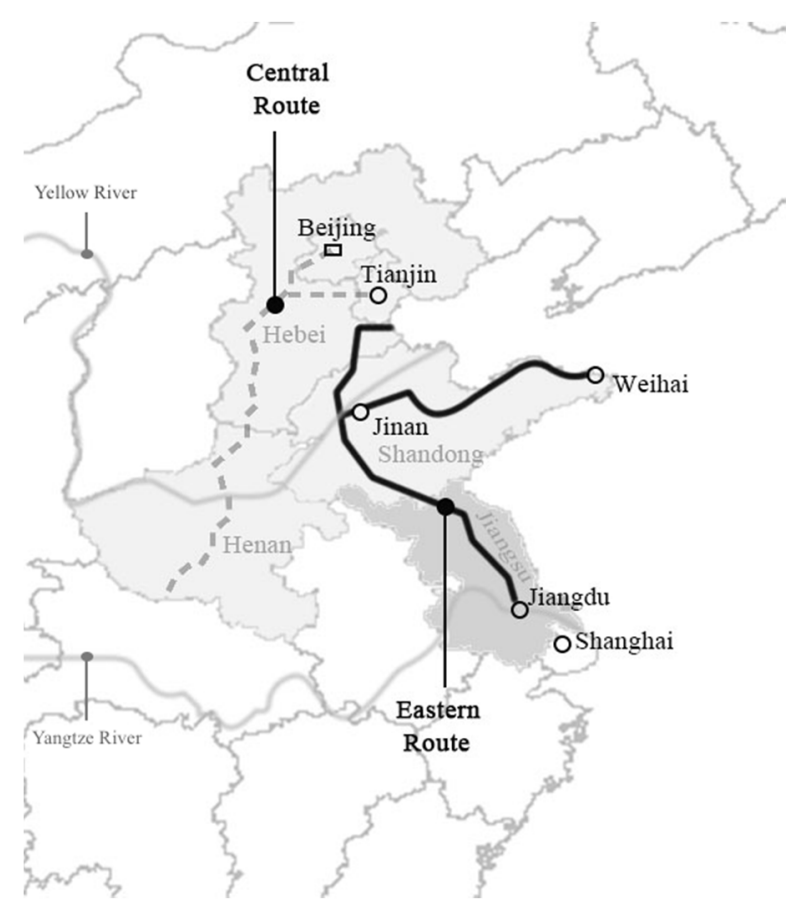

Figure 1. Map of the study area.

\subsection{System Dynamics Modeling}

We implemented a system dynamics methodology by building an analytical framework for modeling complex systems, such as the SNWD Project [32]. This method has been applied to a wide range of water resource management and ecological studies [33-35]. With visualized simulation techniques, a system dynamics platform, Vensim PLE Version 6.3 in this study, can allow for a better understanding of the interrelationships among the variables in a large system.

With respect to conflicts between water supply and demand along the southern and northern cities, the water diversion project creates direct or indirect impacts on urban or regional economic and ecological systems. The interaction mechanism is rather complex, but with a detailed model based on the principles of system dynamics, the architecture becomes apparent. As shown in Figure 2, the entire system is described from the perspective of water demand and water supply (the two circles). To capture the dynamic relationships within the system, the model includes over 50 variables, 14 specified constants, 
and 13 lookup functions. Five subsystems have been framed, i.e., water, agriculture, industry, population and the environment. Each subsystem is mutually interrelated to any of the other subsystems. Connectors establish relationships between the elements in the water diversion system, and information transferred among the connected elements is indicated by the direction of the arrows. All flows will contribute to the stocks of the five main outcome variables (the five rectangles). We select five specific subsystems based on three considerations. First, the agricultural, industrial and residential sectors occupy the vast majority of the overall water demand/supply. Second, the effects of water quantity are actually economic effects, which are reflected by the growth in agriculture and industry. Third, the environmental effects of water quality can be further divided into two parts: the usage of surface resources and the usage of groundwater resources. The former produces wastewater pollution associated with rapid agricultural and industrial development, whereas the latter leads to overexploitation as urbanization accelerates. Both results have severely impacted the environment [36].

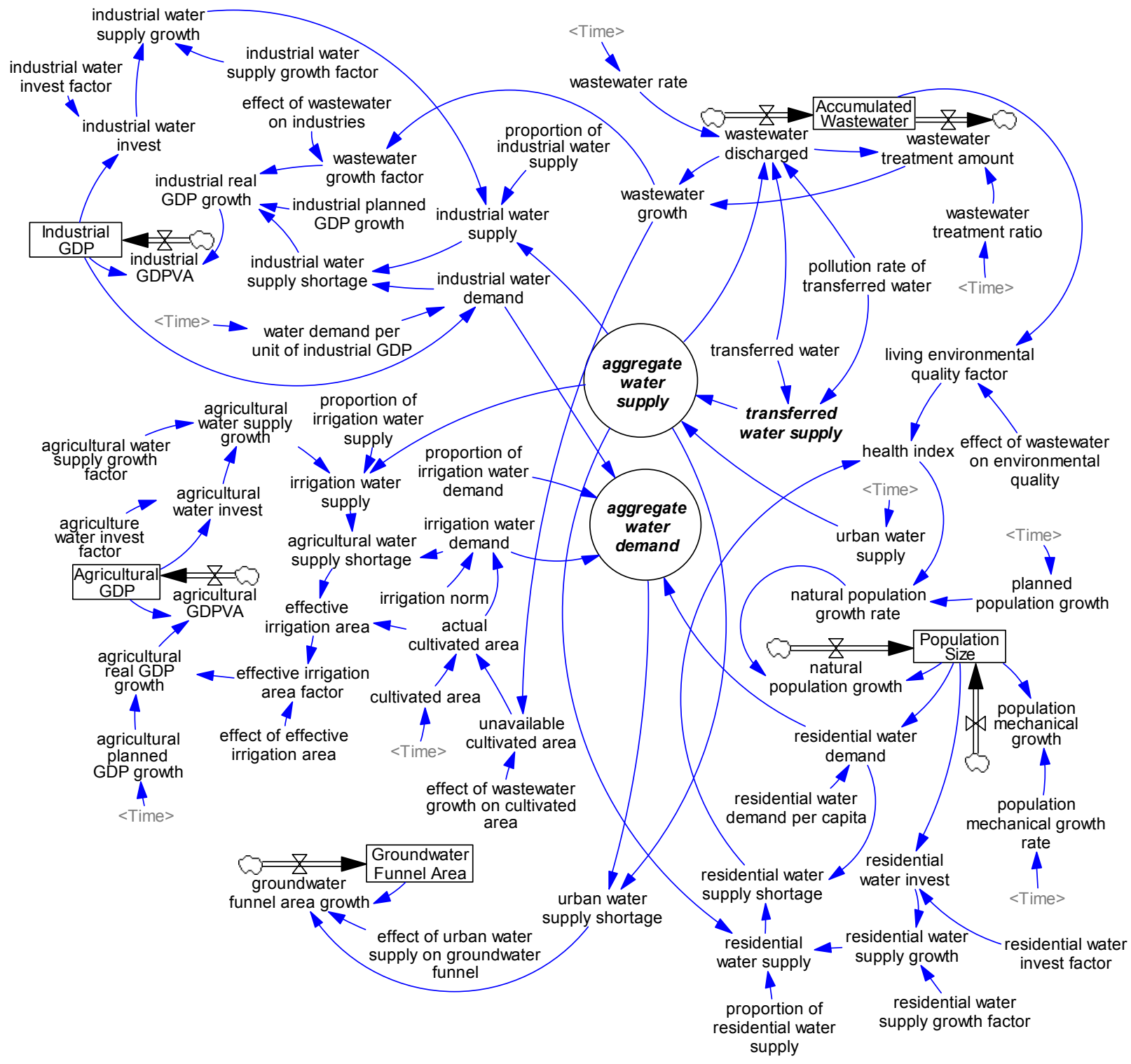

Figure 2. Causal pathways in the system dynamics model. 
This model also includes the effects of accumulations and time delays, as well as impacts from resource constraints and behavioral feedback. The model helps analyze the dynamics caused by the causal relationships between elements in the system and provides insight about reinforcing and balancing feedback loops. Consider the groundwater funnel as an example. The funnel is a certain area where the ground is subsiding due to the excessive pumping of groundwater. North China is the largest subsidence area with the most funnels on the planet, and some regions have even fallen below the sea level. The urban water supply shortage would aggravate the funnel area with an increasing depletion of underground water. If the system receives transferred water, which alleviates the shortage, the groundwater funnel area decreases. From a macro-level perspective, the urban water supply is determined by factors associated with other subsystems, e.g., agricultural demand or the pollution rate of transferred water. The next step of the system dynamics analysis is assigning variables and obtaining the results related to the economic and environmental effects of the SNWD Project.

\subsection{Data}

Data form the major cities located along the diversion route were collected from various official databases and key references, e.g., the Jiangsu Statistical Yearbook and the Jiangsu Water Resources Bulletin. The cities include Yangzhou, Taizhou, Huaian, Yancheng, Suqian, Xuzhou and Lianyungang. Although the formal operation of the eastern route began in late 2013, data between 2002 and 2012 were gathered and calculated. One reason is that the construction of the eastern route began in 2002, and it utilized the existing Grand Canal as the main waterway for water transport. Thus, the impacts from the construction stage are as significant as those from the operational stage, a situation unlike that of the central route. The other reason is the consideration of the accuracy of the data. Model validation can be achieved by comparing the performance of the model to a real system [37]. Before the simulation over the operational period, the system dynamics model was calibrated with the data in the construction period. We obtained desirable results from the comparison between the simulation and historical data, with a bias that was approximately within $4 \%$ for the economic (GDP) data, $0.7 \%$ for the population data and $6 \%$ for the environmental (wastewater, groundwater funnel) data. The validation ensured the data quality indicated in Table 1 . It needs to be clarified that the sum of proportions does not equal 1 because only sectors directly connected with the subsystems in the system dynamics model are counted. Water consumptions from some sectors such as transportation, public facilities and social services (e.g., urban afforestation, firefighting) are far fewer and could be omitted. The proportions listed here have covered nearly 90 percent of the overall water demand or supply.

Some other variables not listed above were also calculated with the latest data available. The two central variables in this research, water quantity and quality, are indicated by the amount of transferred water (TW) and the pollution rate (PR), respectively. The baseline is determined from the integration of official publications. In the feasibility study of the SNWD Project, the annual amount of diverted water before construction was completed was 4.97 billion $\mathrm{m}^{3}$ [38], whereas after the formal operation began, an additional 3.60 billion $\mathrm{m}^{3}$ was diverted, which amounts to an aggregate of 8.57 billion $\mathrm{m}^{3}$ [39]. According to China's National Development and Reform Commission, the actual amount of diverted water in the eastern route is fixed at 14.80 billion $\mathrm{m}^{3}$ [40]. Therefore, we analyzed three water levels: 5,10 and 15 billion $\mathrm{m}^{3}$. Furthermore, we also considered two levels, 30 and 50 billion $\mathrm{m}^{3}$, for the 
scenarios in which the water demand significantly increases with expanding urbanization and economic activities in the near future. With respect to the pollution rate, there is only one reliable source. The People's Daily officially reported that the overall water quality compliance rate was $89 \%$ before the project began its formal operation in 2012 [41]. The data indicate that the pollution rate is approximately $10 \%$.

Table 1. Initial values and sources of some key variables.

\begin{tabular}{ccc}
\hline Variables & $\begin{array}{c}\text { Initial Values } \\
(\text { Year }=\mathbf{2 0 1 2})\end{array}$ & Units and Data Sources \\
\hline proportion of irrigation water supply & 66.45 & $\begin{array}{c}\text { \%, Jiangsu Water Resources Bulletin } \\
\text { million } \mathrm{m}^{3} \text { per thousand hectare, Jiangsu Water } \\
\text { Resources Bulletin }\end{array}$ \\
irrigation norm & 649.50 & \%, Jiangsu Water Resources Bulletin \\
proportion of irrigation water demand & 88.64 & \%, Jiangsu Water Resources Bulletin \\
proportion of industrial water supply & 14.00 & \%, Jiangsu Water Resources Bulletin \\
proportion of residential water supply & 7.00 & billion Yuan, Jiangsu Statistical Yearbook \\
agricultural GDP & 154.58 & billion Yuan, Jiangsu Statistical Yearbook \\
industrial GDP & 483.52 & ten thousand, Jiangsu Statistical Yearbook \\
population size & 3400.82 & billion m m $^{3}$, authors' assumption \\
accumulated wastewater & 0 & thousand hectare, Jiangsu Water \\
groundwater funnel area & 150 & Resources Bulletin \\
\hline
\end{tabular}

To assess the effects of changes in water quantity and quality, we run simulations through the year 2020. The results offer stakeholders and policy-makers new perspectives for understanding the interaction of water quantity and quality, as well as the trajectory of sustainable water management.

\section{Results}

This section reports on four outcome variables: agricultural and industrial GDP as two economic indicators, and accumulated wastewater and the groundwater funnel area as two environmental indicators. The results concerning population are omitted, because the annual changes are minor (within approximately $0.2 \%$ ). Although the model provides results through 2020, its purpose is not to predict exact forecasts, but to offer insight into how the economic and environmental systems tend to respond to water quantity and quality.

\subsection{Different Transferred Water Levels}

As explained in the previous section, we chose five different levels of transferred water amounts to simulate the effects of quantity on economics and the environment. The results obtained for the four variables are listed in Figure 3. Five curves of accumulated wastewater can be observed. A higher level of water diversion accumulates more pollution, which is clearly attributed to the open water system along the eastern route. The effects on the three other variables are inconspicuous, which is partially a result of the unit setting. If the billions unit is replaced by hundred millions (cubic meters or Yuan), which is the official unit in China, the gap between the fives curves will become more distinct. To better present the results, specific simulated values for the three variables from 2015 to 2020 are listed in Table 2 . 


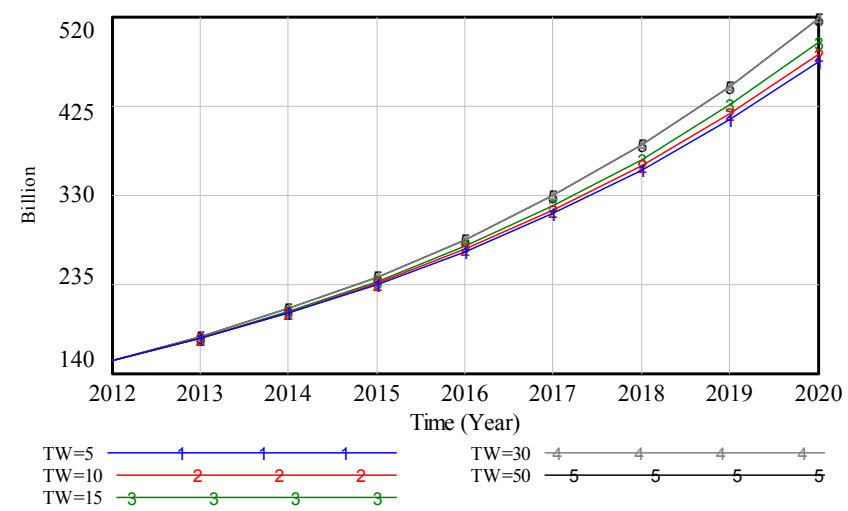

(a)

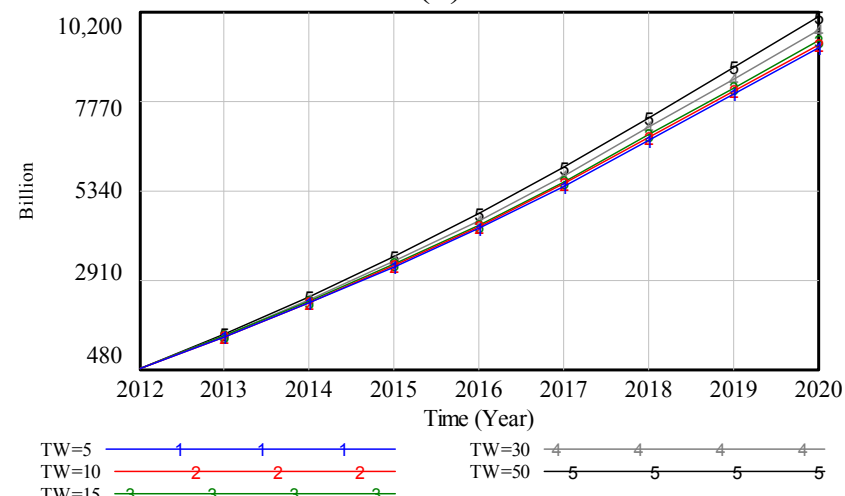

(b)
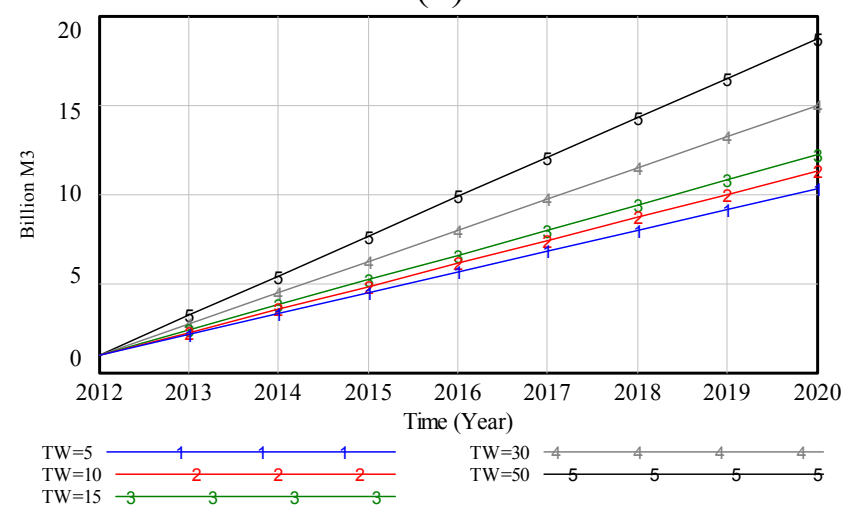

(c)

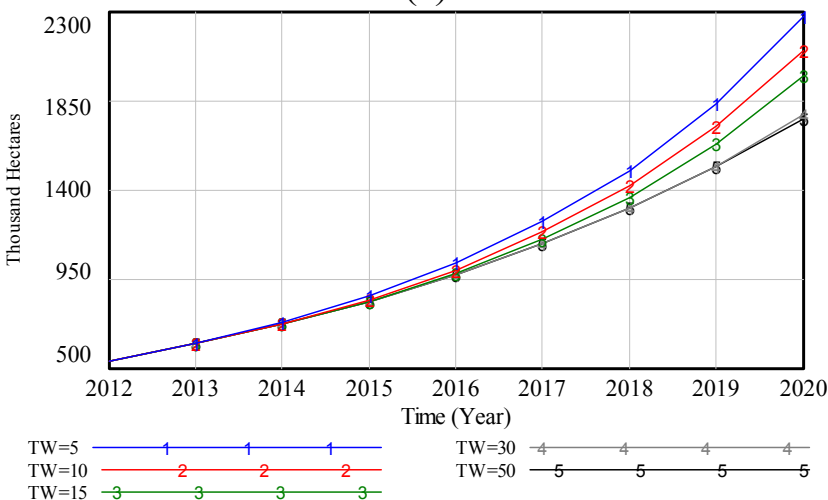

(d)

Figure 3. Economic and environmental effects respond to different transferred water (TW) levels. (a) Agricultural GDP; (b) Industrial GDP; (c) Accumulated Wastewater; (d) Groundwater Funnel Area. 
Table 2. Outcomes as water quantity changes, 2015-2020.

\begin{tabular}{cccccccc}
\hline \multirow{2}{*}{ Outcome Variables } & $\begin{array}{c}\text { Transferred } \\
\text { Water }(\mathbf{T W})\end{array}$ & $\mathbf{2 0 1 5}$ & $\mathbf{2 0 1 6}$ & $\mathbf{2 0 1 7}$ & $\mathbf{2 0 1 8}$ & $\mathbf{2 0 1 9}$ & $\mathbf{2 0 2 0}$ \\
\hline & $\mathrm{TW}=5$ & 234.02 & 269.18 & 309.68 & 356.34 & 410.10 & 472.10 \\
Agricultural GDP & $\mathrm{TW}=10$ & 235.64 & 271.65 & 313.20 & 361.14 & 416.47 & 480.36 \\
(billion Yuan) & $\mathrm{TW}=15$ & 237.84 & 275.03 & 318.06 & 367.87 & 425.53 & 492.30 \\
& $\mathrm{TW}=30$ & 242.62 & 282.38 & 328.66 & 382.53 & 445.23 & 518.20 \\
& $\mathrm{TW}=50$ & 242.62 & 282.38 & 328.66 & 382.53 & 445.23 & 518.20 \\
\hline \multirow{3}{*}{ Industrial GDP } & $\mathrm{TW}=5$ & 3253.95 & 4309.78 & 5451.21 & 6692.87 & 7940.09 & 9192.91 \\
(billion Yuan) & $\mathrm{TW}=10$ & 3288.38 & 4357.32 & 5512.86 & 6769.82 & 8032.35 & 9300.49 \\
& $\mathrm{TW}=15$ & 3321.49 & 4403.01 & 5572.11 & 6843.77 & 8121.01 & 9403.85 \\
& $\mathrm{TW}=30$ & 3412.82 & 4529.04 & 5735.50 & 7047.63 & 8365.33 & 9688.63 \\
& $\mathrm{TW}=50$ & 3532.34 & 4693.98 & 5949.36 & 7314.47 & 8685.17 & 10061.50 \\
\hline \multirow{3}{*}{ Groundwater funnel } & $\mathrm{TW}=5$ & 861.45 & 1027.99 & 1236.27 & 1496.83 & 1830.78 & 2271.35 \\
area (thousand & $\mathrm{TW}=10$ & 843.18 & 994.75 & 1183.14 & 1417.19 & 1715.61 & 2097.92 \\
hectare) & $\mathrm{TW}=15$ & 836.75 & 975.81 & 1147.70 & 1359.88 & 1629.20 & 1972.49 \\
& $\mathrm{TW}=30$ & 836.75 & 970.63 & 1125.93 & 1306.08 & 1515.55 & 1779.62 \\
\hline & $\mathrm{TW}=50$ & 836.75 & 970.63 & 1125.93 & 1306.08 & 1515.05 & 1757.46 \\
\hline
\end{tabular}

The vertical comparison reveals a similar pattern for the agricultural GDP as well as the groundwater funnel area. As indicated by the grey shading areas in Table 2, the agricultural GDP is constant after the amount of transferred water reaches 30 billion $\mathrm{m}^{3}$, implying that a growth limitation may have been reached. The decreasing trend of the groundwater funnel area would end at the same amount of transferred water. The termination begins even earlier in 2015, at a level of 15 billion $\mathrm{m}^{3}$, and exhibits a slower pace in 2019 and 2020. The similarity is primarily caused by the natural characteristics of these two variables. Given the current technology used for agricultural cultivation and groundwater exploitation, there is limited potential for improvements despite the massive water diversion $[42,43]$. These results also validate the rationale for the planned amount of diverted water [38,39].

The situation is different for industries. The industrial GDP would increase by 50-100 billion Yuan with an extra five billion $\mathrm{m}^{3}$ of water supply and increase by 100-300 billion Yuan with an additional 15-20 billion $\mathrm{m}^{3}$ of water supply. Because the natural restrictions on industries are not considerable, industrial growth always produces a majority of the pollution, which should not continue without limit [44]. In determining whether to avoid the negative environmental aftereffects, there exists a conflict that is precisely the central issue addressed in this study. What effects would the interaction between the changes in water quantity and water quality generate? The next step of the calculation will attempt to offer additional solutions.

\subsection{Different Pollution Rate Levels}

The adjustments to transferred water suggest a rational amount not to exceed 30 billion $\mathrm{m}^{3}$ to prevent inefficiency. Thus, the following simulation will examine scenarios that change the pollution rate for a certain level of transferred water. In each particular case, we test the water quality effects of a pollution rate at the current $10 \%$ condition, and for two additional scenarios: $5 \%$ as an improvement in water quality and $15 \%$ as deterioration. As shown in Figure 4 , with a pollution rate ranging from $5 \%$ to 
$10 \%$ and $15 \%$, there is an increasing accumulation of wastewater at various amounts of transferred water. The detailed simulation results of the three other outcome variables are also reorganized in Table 3 for reference.

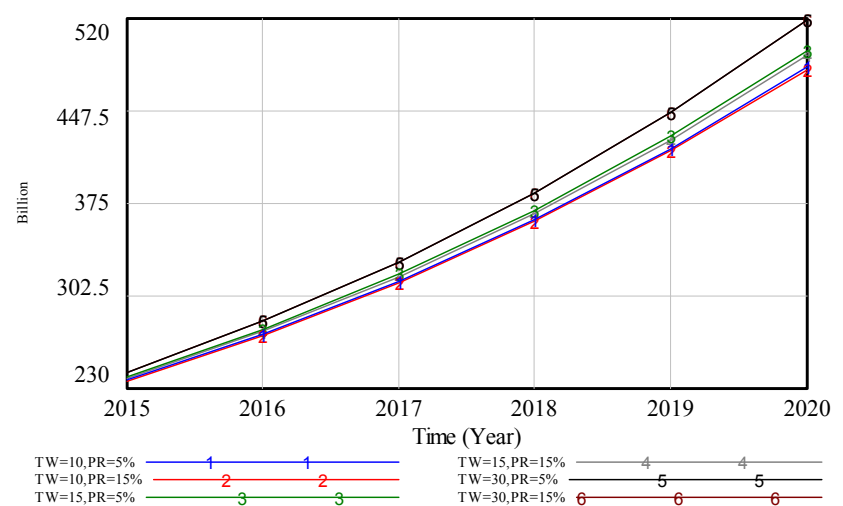

(a)

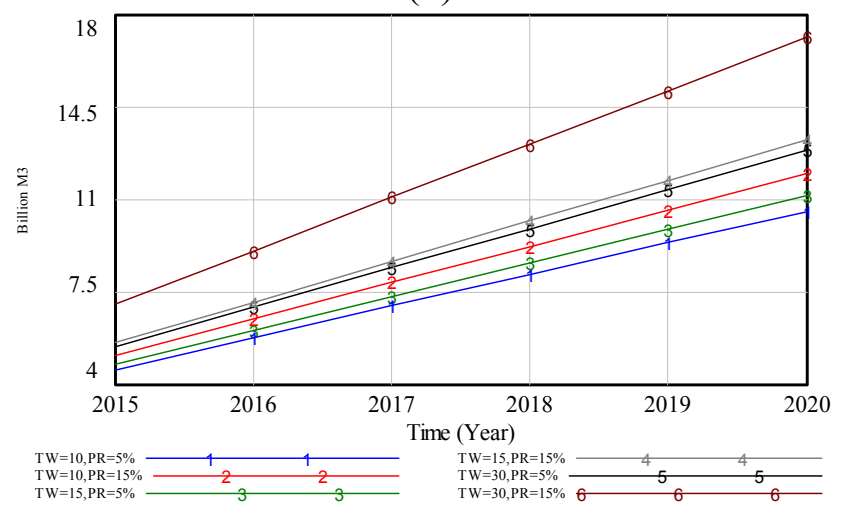

(c)

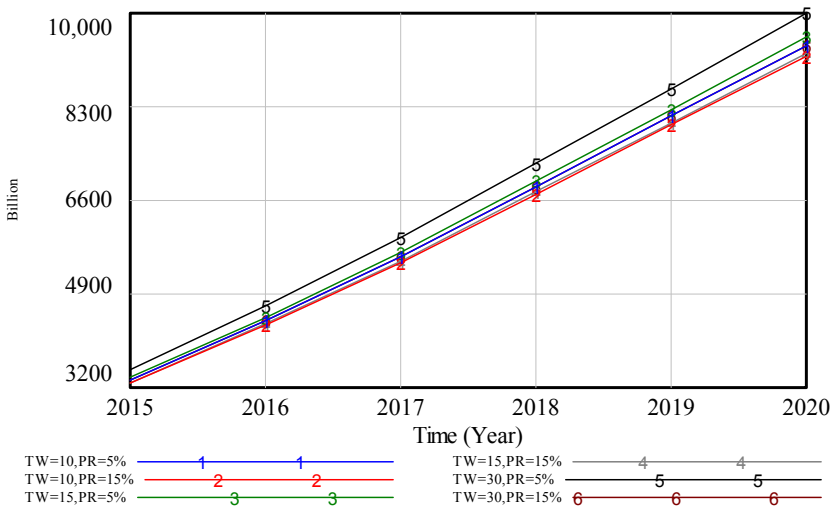

(b)

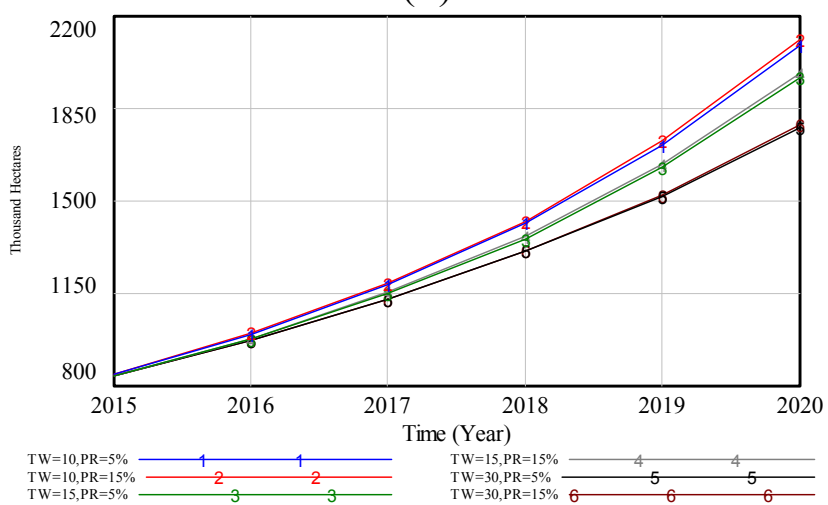

(d)

Figure 4. Economic and environmental effects response to different pollution rate (PR) levels (a) Agricultural GDP; (b) Industrial GDP; (c) Accumulated Wastewater; (d) Groundwater Funnel Area.

Table 3. Outcomes as water quality changes, 2015-2020.

\begin{tabular}{|c|c|c|c|c|c|c|c|}
\hline $\begin{array}{l}\text { Outcome } \\
\text { Variables } \\
\end{array}$ & $\begin{array}{c}\text { Transferred Water (TW), } \\
\text { Pollution Rate (PR) } \\
\end{array}$ & 2015 & 2016 & 2017 & 2018 & 2019 & 2020 \\
\hline \multirow{9}{*}{$\begin{array}{l}\text { Agricultural } \\
\text { GDP } \\
\text { (billion Yuan) }\end{array}$} & $\mathrm{TW}=10, \mathrm{PR}=15 \%$ & 235.40 & 271.27 & 312.64 & 360.36 & 415.41 & 478.96 \\
\hline & $10 \%$ & +0.25 & +0.39 & +0.56 & +0.78 & +1.06 & +1.40 \\
\hline & $5 \%$ & +0.26 & +0.41 & +0.59 & +0.81 & +1.10 & +1.44 \\
\hline & $\mathrm{TW}=15, \mathrm{PR}=15 \%$ & 238.19 & 275.58 & 318.86 & 368.97 & 427.02 & 494.27 \\
\hline & $10 \%$ & +0.36 & +0.55 & +0.79 & +1.10 & +1.48 & +1.96 \\
\hline & $5 \%$ & +0.36 & +0.55 & +0.79 & +1.10 & +1.49 & +1.97 \\
\hline & $\mathrm{TW}=30, \mathrm{PR}=15 \%$ & 242.62 & 282.38 & 328.66 & 382.53 & 445.23 & 518.20 \\
\hline & $10 \%$ & 0 & 0 & 0 & 0 & 0 & 0 \\
\hline & $5 \%$ & 0 & 0 & 0 & 0 & 0 & 0 \\
\hline
\end{tabular}


Table 3. Cont.

\begin{tabular}{|c|c|c|c|c|c|c|c|}
\hline $\begin{array}{l}\text { Outcome } \\
\text { Variables }\end{array}$ & $\begin{array}{c}\text { Transferred Water (TW), } \\
\text { Pollution Rate (PR) } \\
\end{array}$ & 2015 & 2016 & 2017 & 2018 & 2019 & 2020 \\
\hline \multirow{9}{*}{$\begin{array}{l}\text { Industrial GDP } \\
\text { (billion Yuan) }\end{array}$} & $\mathrm{TW}=10, \mathrm{PR}=15 \%$ & 3258.98 & 4316.61 & 5459.90 & 6703.49 & 7952.55 & 9207.10 \\
\hline & $10 \%$ & +29.40 & +40.71 & +52.96 & +66.33 & +79.80 & +93.39 \\
\hline & $5 \%$ & +29.52 & +40.87 & +53.17 & +66.60 & +80.13 & +93.76 \\
\hline & $\mathrm{TW}=15, \mathrm{PR}=15 \%$ & 3276.78 & 4341.11 & 5491.58 & 6742.91 & 7999.67 & 9261.87 \\
\hline & $10 \%$ & +44.71 & +61.90 & +80.53 & +100.86 & +121.34 & +141.98 \\
\hline & $5 \%$ & +44.97 & +62.26 & +81.00 & +101.45 & +122.05 & +142.82 \\
\hline & $\mathrm{TW}=30, \mathrm{PR}=15 \%$ & 3321.10 & 4402.08 & 5570.35 & 6840.82 & 8116.55 & 9397.56 \\
\hline & $10 \%$ & +91.72 & +126.96 & +165.15 & +206.81 & +248.78 & +291.07 \\
\hline & $5 \%$ & +94.08 & +130.24 & +169.44 & +212.20 & +255.29 & +298.71 \\
\hline \multirow{9}{*}{$\begin{array}{l}\text { Groundwater } \\
\text { funnel area } \\
\text { (thousand } \\
\text { hectare) }\end{array}$} & $\mathrm{TW}=10, \mathrm{PR}=15 \%$ & 844.02 & 996.62 & 1186.28 & 1421.93 & 1722.33 & 2107.11 \\
\hline & $10 \%$ & -0.84 & -1.86 & -3.14 & -4.74 & -6.72 & -9.19 \\
\hline & $5 \%$ & -0.84 & -1.86 & -3.12 & -4.71 & -6.66 & -9.11 \\
\hline & $\mathrm{TW}=15, \mathrm{PR}=15 \%$ & 836.75 & 977.09 & 1150.53 & 1364.61 & 1636.23 & 1982.33 \\
\hline & $10 \%$ & 0 & -1.28 & -2.83 & -4.73 & -7.03 & -9.84 \\
\hline & $5 \%$ & 0 & -1.27 & -2.81 & -4.7 & -6.96 & -9.72 \\
\hline & $\mathrm{TW}=30, \mathrm{PR}=15 \%$ & 836.75 & 970.63 & 1125.93 & 1306.08 & 1517.77 & 1784.2 \\
\hline & $10 \%$ & 0 & 0 & 0 & 0 & -2.22 & -4.58 \\
\hline & $5 \%$ & 0 & 0 & 0 & 0 & -0.50 & -2.48 \\
\hline
\end{tabular}

Notes: "+"/“-"denotes the relative increase/decrease of the results above; "0" indicates no change.

It should be noted that the agricultural GDP and groundwater funnel area would stabilize after reaching a certain level of transferred water. This situation is mostly consistent with the results in Section 3.1, even though the pollution rate varies. This result further verifies the potential limits on the water demand from agriculture. Below a fixed level $(\mathrm{TW}=30)$, these two variables would change at a different pollution level. Less-polluted water could promote agricultural growth. The water quality is increasingly critical in the long run (2018-2020), when a 5\% improvement in the pollution rate could produce an additional 1-2 billion Yuan in agricultural GDP and reduce approximately 5-10 thousand hectares of the groundwater funnel area.

An exception to the case of TW $=30$ is the groundwater funnel area in the long term, i.e., 2019 and 2020, when a lower pollution rate results in a lower funnel area. This change might be correlated with the interactions of population growth, residential water demand and supply shortage. In the long run, the residential population will increase to a significantly high level as a result of urbanization. It is assumed that the population size will have a positive impact on the residential water demand. Thus, the effective water supply will be negatively correlated with the pollution rate, whereas the groundwater funnel area, which depends on a water supply shortage, will exhibit a notable decrease.

The most important results are the impacts due to both water quantity and water quality on the industrial GDP. The simulation updates the understanding of the unsolved issue discussed in Section 3.1. It demonstrates that more investment in pollution treatment would stimulate industrial growth. The industrial GDP would increase by approximately 30-150 billion Yuan with a 5\% upgrade in water quality between 2015 and 2018 and increase by as much as 300 billion Yuan from 2017 to 2020. 
Furthermore, the effect from the additional water quantity could reinforce the water quality impacts. The simulation has also indirectly demonstrated the growth limitation of industries, although no obvious natural restrictions exist, such as those on agriculture or groundwater. If we were to compare the gains from better water quality and the costs of pollution treatment, the findings would be more meaningful. According to a public data source, 15.4 billion Yuan has been devoted to water pollution control [45]. This investment could easily be offset by the economic gains from the extra growth in the industrial GDP.

\section{Discussions}

\subsection{Trade-Offs in the SNWD Project}

The simulations in the previous section have provided definite answers to the central question raised in this paper. There is no contradiction between the quantity and quality of diverted water. It is clear that economic and social development in regions with water shortages requires that more water be made available and that the SNWD Project could vastly improve the situation. Furthermore, the quality of transferred water is equally essential to the sustainable growth of the water-receiving areas. Environmental limitations exist in all economic activities, including agriculture and industry, as well as the urban expansion that creates more groundwater funnels. Therefore, the water diversion program should address the economic dimension and also avoid the imminent conflict with the water environment.

The preliminary findings have shown that the water quantity-quality trade-off could obtain a point of equilibrium, while this trade-off is not the only one in the SNWD Project. In the simulations of various subsystems, despite the minor changes in population, another potential trade-off exists between agriculture and industry. This trade-off is essentially a comparison between marginal costs and marginal benefit. As for the agricultural sector, it is related to the safeguarding of the national food security in China [46]. The simple calculation on the water usage and the economic output is not sufficient for the social optimization, especially when its production and yields would decrease due to urbanization [47]. As for the industrial sector, it has contributed the majority in the GDP accumulation, yet with even more pollution and violating social welfare [44]. Therefore, there exists a certain side effect in the water diversion, i.e., the results show no limitation for industrial growth in Section 3.1. For the purpose of realizing synergy among economic, social and environmental goals, it is necessary to build a multi-objective coordination model for the SNWD supply system. The trade-off between water resource allocation and quality protection is a fundamental issue. Meanwhile, the full consideration of the production decision-making and related by-products in agricultural, industrial and other sectors is a prerequisite as well. Without this mechanism, there might be some obstructions to achieving the ideal results of water quantity and quality in Section 3.

The research findings presented above are straightforward, one reason possibly being the study area of focus. We focused on a single province, so that certain other factors could be ignored. If we were to include other provinces, the analysis and simulation model would be more complicated. Because the conflicts and coordination between provincial boundaries are increasingly significant [48], the political dimension factors are difficult to describe in the quantitative model. Furthermore, in this case, we should also consider that the central government would be involved, making the entire conflict 
hierarchical [49]. Thus the third trade-off between provincial boundaries, or between central and local governments, would make a further renegotiation and possibly change the designed water quantity and quality proposals.

\subsection{Further Stages under Planning}

The SNWD Project has yet to be fully accomplished. As described in Section 2.1, the completed project in late-2013 was the first stage of the eastern route. Thus, the quantitative analysis in the sections above was actually based on the conditions and data in that early stage. Findings from the simulation did not take the new project construction into consideration.

When discussing the upcoming second stage that remains in the planning process, a more comprehensive thinking is required. Though some explicit predictions have been achieved, they need to be combined with some other real-world policies. The most considerable one is from the State Council of China. In January 2013, the No. 2013-2 Document "Assessment Methods for the Most Strict Water Resource Management System" was issued. The policy outlines the principles of China's water resource management from a macro perspective. It sets the overall national water consumption on a limitation of 700 billion $\mathrm{m}^{3}$ per year, as well as the control targets for every province. Among them, Jiangsu Province is given a quota restriction of 50.8 billion $\mathrm{m}^{3}$ in 2015 , and 52.4 billion $\mathrm{m}^{3}$

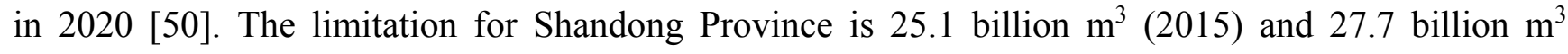
(2020), while for Tianjin, it is 2.8 billion $\mathrm{m}^{3}$ and 3.8 billion $\mathrm{m}^{3}$, respectively. Comparing with the results in Section 3.1, the amount of transferred water is equivalent to nearly 60 percent of Jiangsu's total water supply. It would significantly relieve stresses for the water consumption in both Shandong and Tianjin. However, the water quantity-controlling regime has brought more significant pressure for Jiangsu. Related evidence is the No. 2011-29 Document "The Water Resource Planning in Jiangsu Province" from the Water Resources Department of Jiangsu Province. The planning goal of water usage in 2020 is 59 billion $\mathrm{m}^{3}$ [51]. However, the State Council cut this standard down 6.6 billion $\mathrm{m}^{3}$ two years later in the No. 2013-2 Document.

The solution for this rigorous situation is quite complicated, while the analysis in Section 3.2 might put forward a workable suggestion. Since the water quality has a specific connection with the water diversion amount, the control of the pollution rate could be the breakthrough point. A reduced pollution level leads to a higher efficiency of water consumption. For example, in 2020, the industrial GDP for the case of TW $=15$ and $\mathrm{PR}=10 \%$ (9403.85 billion) is greater than the case of $\mathrm{TW}=30$ and $\mathrm{PR}=15 \%$ (9397.56 billion). If the water quality could be improved in the following years, the targeted water supply goal would not be a problem for Jiangsu. Therefore, the outputs of the first stage are the inputs for the second stage. With an increasing demand in the second stage, it is necessary for water providing regions to establish a clear objective system on water quality upgrading so as to enhance the current usage efficiency and to satisfy the further needs from the northern provinces and even the capital.

\subsection{Some Neglected Factors}

The research on the water quantity-quality interaction has covered several factors including economic, social and ecological dimensions. Meanwhile, the system dynamics model has its unique 
advantage in describing the effects of water diversion from various perspectives. However, some key influential factors are still missing.

This study has only predicted the case for the time horizon up to the year 2020, which is based on an implicit assumption that no eventful technological or structural change will occur. Thus, all of the results pertain to the current technological conditions. While it is increasingly emphasized in China that local governments put huge efforts into the research and development of techniques with water efficiency and pollution control [52], the results in the next five years would possibly change. In view of this surmise, it could be optimistic about the potential difficulties in further project stages under planning.

The structural characteristics of the various economic sectors have also been considered to remain unchanged. This means that the initial proportion settings in Table 1 are relatively stable during the eight-year simulation period. Most of the graphs indicate exponential growth curves, corresponding to the ongoing and upcoming high-speed growth in China. The growth rate is extraordinarily high for Jiangsu Province, especially for its north and central regions (the cities included in this study), which have annual GDP growth rates over 12 percent and industrial growth rates of nearly 14 percent [53]. However, we could expect that in the long run, more significant technological progresses will occur, with a transformed industrial structure, and the flow and stock of the outcome variables would differ. Currently, the transforming degrees in the agriculture (first) sector are relatively low, since the changes of its share in GDP were less than 0.2 percent in the recent five years. The changes are more clear and satisfying in the industrial (second) sector, with the annual declining rates between one and 1.4 percent [53]. Thus, a transition to an s-shaped curve would occur a few decades later, when the parameters given in this study fundamentally change. This trend will bring a remission to the water consumption pressure, especially for the providing regions. Meanwhile, the central and local governments would definitely push forward the acceleration of economic structural transformation [54]. This is a factor of policy and will be discussed in the next paragraphs.

For a great national infrastructure project, the influence of the policy dimension is crucial, as well. Most of this paper presented an engineering perspective by setting different water transfer and pollution rate levels, which is independent of policy. All of the initial parameters have been partially determined by central or local policies and stabilized after years of evolution. Governments have the ability to co-opt environmental policies to pursue other strategic objectives [55]. As the SNWD Project has completed its construction stage and begun formal operations, the influence from policy-makers, rather than engineers, should be allotted more significance.

There are three priority factors related to policies. The first is the water price mechanism. Although the Jiangsu Water Source Company Ltd., on behalf of the provincial government, is charged with the water market businesses, including water price setting, water is a special product that is a necessity for the basic needs of residents and farmers. Water consumption could not be handled totally under commercial principles. Water-providing areas have complained about the costs they bear as part of the SNWD water treatment and other issues. The central government is requested to impose an "SNWD tax" on beneficiaries of the project [56]. If similar tax or subsidy policies are introduced into the water price mechanism, an ideal condition that makes the marginal costs approximate the marginal revenue could be formed. In an economic view, the efficiency of water usage would increase significantly under a better price mechanism. As a consequence, the results of the water transfer amounts in Section 3.1 could reduce accordingly. The second is the water pollution control mechanism. Prior to 
the operation of the SNWD Project, over 400 pollution prevention projects, with a total investment over 15 billion Yuan, have been implemented in the water quality programs of the eastern route [57]. However, the decentralized regime in China and in this project has weakened local environment agencies, and the pollution fees from firms are often too low [58]. As a national infrastructure project, local officials should receive powerful support from the central governments. With the incentives of the pilot program on Water Ecological Civilization Cities [59], greater efforts in monitoring and detecting water pollution, advocating for responsive policies in local levels will lead to an improvement in water quality. Last, but not least, social participation is substantial. It is critical for both water quantity and water quality. As for the water consumption, policies focusing on social concerns with education programs implemented for water conservation could reduce individual daily water usages. Meanwhile, calling for stronger institutionalized public engagements would create a culture of conservation and provide a strong impetus for addressing water pollution [60].

Furthermore, we only treat the water quantity and quality as exogenous variables. Some endogenous factors, such as biological and chemical ones, are highly relevant to water quality, as well. Future climate conditions that might affect economic (especially agriculture) and environmental indicators are also unknown. Further research on those factors might be helpful to better understanding the findings in this study.

\section{Conclusions and Policy Implications}

This study uses the system dynamics method to analyze the interaction between water quantity and water quality in China's SNWD Project. The economic and environmental effects for various scenarios of transferred water and pollution rates are calculated. This research differs from other work in that we choose a specific province, covering both the water-providing and water-receiving areas. Although the system dynamics model and other mathematical tools have been used in other studies in the past, most of those studies have treated the factors of quantity and quality separately. In our model, five subsystems of water, agriculture, industry, population and the environment are included simultaneously, and data from 2002 to 2012 are collected. We develop simulations through the year 2020 to assess water quantity and quality effects and to obtain insight into sustainable water management in the related areas.

Based on the simulation results obtained for the economic and environmental indicators at the different levels of water quantity and water quality, certain conclusions can be drawn. First, the SNWD Project could provide a sufficient quantity of water for economic growth in the receiving regions. Second, an efficient quantity of transferred water exists, which demonstrates the growth limitation for both agriculture and the groundwater funnel. Third, upgrades in water quality could mutually reinforce the quantity effect and greatly promote economic growth, as well. Environmental limitation exists in all economic activities. Therefore, from a general perspective, both water quantity and water quality are equally crucial in the SNWD Project. The water diversion project is not only intended to reduce water constraints; it is also an opportunity to promote sustainable development and the establishment of an ecologically conscious civilization [61]. These findings also provide certain policy implications for the government and the public.

The source of the SNWD eastern route is the Yangtze River, the longest in Asia and the third longest in the world, and its downstream could provide almost a limitless water supply. This study 
shows that although the water source has no natural limitation, the use of it has environmental limitations for all economic activities. Therefore, an essential policy recommendation is that the operational stage of the SNWD Project requires a transition from efficient water diversion to effective water diversion. This means greater priority should be given to providing a sufficient amount of drinking and nondrinking water of high quality, rather than simply satisfying the water shortage with a specific amount of water. In practice, local governments also face the dilemma of low water prices and high water use efficiency, with the aim of satisfying economic needs, as well as environmental objectives [62]. Thus, certain regulations should be employed. Typical policy choices for some local governments include economic incentives, such as water quality permit trading or the use of environmental taxes (e.g., the "SNWD tax"). The central government needs to launch a water-quality-based control program with higher water quality criteria and stringent environmental legislation. Additionally, in terms of residential water usage, non-governmental participation and the promotion of water conservation awareness might also be necessary.

\section{Acknowledgments}

This research was financially supported by the Social Science Foundation (Youth Project) of Jiangsu Province (Grant No. 14ZHC001), the Social Science Foundation (Key Project) of Jiangsu Province (Grant No. 13ZHA001) and the Science and Technology Innovation Project on the South-to-North Water Diversion Project (Grant No. NSBDKJCX-2013-01). The authors would like to thank the reviewers for providing valuable comments that helped us to improve the manuscript.

\section{Author Contributions}

$\mathrm{Yu}$ Yang performed the research, wrote the paper and validated the results. Lei Yin collected original data and analyzed the results. Qingzong Zhang provided background materials and suggestions for reviewing the manuscript throughout the entire writing process. All authors read and approved the final manuscript.

\section{Conflicts of Interest}

The authors declare no conflict of interest.

\section{References}

1. Freeman, C. Quenching the Dragon's Thirst: The South-North Water Transfer Project — Old Plumbing for New China? Available online: http://www.wilsoncenter.org/publication/quenching-the-dragonsthirst-the-south-north-water-transfer-project8212old-plumbing-for (accessed on 30 September 2014).

2. China Daily. Flow Test for Water Project Gets Underway. Available online: http://usa.chinadaily. com.cn/epaper/2013-05/31/content_16552718.htm (accessed on 13 October 2014).

3. A Total Investment of 208.6 Billion in Central Route. Available online: http://finance.sina.com.cn/ china/20140704/052719605525.shtml (accessed on 10 December 2014).

4. World Bank. China 2020: Issues and Options for China; World Bank: Washington, DC, USA, 1997.

5. World Bank. Agenda for Water Sector Strategy for North China; World Bank: Washington, DC, USA, 2001. 
6. Feng, S.; Li, L.X.; Duan, Z.G.; Zhang, J.L. Assessing the impacts of South-to-North Water Transfer Project with decision support systems. Decis. Support Syst. 2007, 42, 1989-2003.

7. Le Mentec, K. The Three Gorges Dam and the demiurges: The story of a failed contemporary myth elaboration in China. Water Hist. 2014, 6, 1-19.

8. Barca, S. Telling the right story: Environmental violence and liberation narratives. Environ. Hist. 2014, 20, 535-546.

9. Chellaney, B. Water, power, and competition in Asia. Asian Surv. 2014, 54, 621-650.

10. James, K.R. Policy and Planning for Large Water Infrastructure Projects in the People's Republic of China, Doctoral Dissertation, Wesleyan University, Wesleyan, CT, USA, 2013.

11. He, C.; He, X.; Fu, L. China's South-to-North Water Transfer Project: Is it needed? Geogr. Compass 2010, 4, 1312-1323.

12. Chen, X.; Zhang, D.; Zhang, E. The south to north water diversions in China: Review and comments. J. Environ. Plan. Manag. 2002, 45, 927-932.

13. Liu, C.; Zheng, H. South-to-north water transfer schemes for China. Int. J. Water Resour. Dev. 2002, $18,453-471$.

14. Wang, W.; Gao, L.; Liu, P.; Hailu, A. Relationships between regional economic sectors and water use in a water-scarce area in China: A quantitative analysis. J. Hydrol. 2014, 515, 180-190.

15. Changming, L. Environmental issues and the south-north water transfer scheme. China Quart. 1998, 156, 899-910.

16. Kim, H.S. Sustainable development and the South-to-North Water Transfer Project in China. Doctoral Dissertation, Central Connecticut State University, New Britain, CT, USA, 2003.

17. Wei, S.; Yang, H.; Abbaspour, K.; Mousavi, J.; Gnauck, A. Game theory based models to analyze water conflicts in the Middle Route of the South-to-North Water Transfer Project in China. Water Res. 2010, 44, 2499-2516.

18. Berkoff, J. China: The South-North Water Transfer Project-Is it justified? Water Policy 2003, 5, $1-28$.

19. Ma, J.; Hoekstra, A.Y.; Wang, H.; Chapagain, A.K.; Wang, D. Virtual versus real water transfers within China. Philos. Trans. R. Soc. B 2006, 361, 835-842.

20. Zhao, X.; Liu, J.; Liu, Q.; Tillotson, M.R.; Guan, D.; Hubacek, K. Physical and virtual water transfers for regional water stress alleviation in China. Proc. Natl. Acad. Sci. USA 2015, 112, 1031-1035.

21. China Daily. China's New Grand Canal Brings Water to Arid North. Available online: http://usa. chinadaily.com.cn/china/2014-12/16/content_19093457.htm (accessed on 18 December 2014).

22. Gu, W.; Shao, D.; Jiang, Y. Risk evaluation of water shortage in source area of middle route project for South-to-North Water Transfer in China. Water Resour. Manag. 2012, 26, 3479-3493.

23. Berrittella, M.; Rehdanz, K.; Tol, R.S. The Economic Impact of the South-North Water Transfer Project in China: A Computable General Equilibrium Analysis; Working Papers FNU-117; Research unit Sustainability and Global Change, Hamburg University: Hamburg, Germany, 2006.

24. Zhang, Q. The South-to-North Water Transfer Project of China: Environmental implications and monitoring strategy. J. Am. Water Resour. Assoc. 2009, 45, 1238-1247.

25. Liu, J.; Yang, W. Water sustainability for China and beyond. Science 2012, 337, 649-650.

26. Chen, H.; Wenger, R.B. Water Diversion Projects in China. In Securing Water and Wastewater Systems: Global Experiences; Clark, R.M., Hakim, S., Eds.; Springer International Publishing: Cham, Switzerland, 2014; pp. 213-232. 
27. International Rivers. Resettlement in Action: An Eyewitness Report from the Middle Route of China's South-North Water Transfer Project. Available online: http://www.internationalrivers.org /files/attached-files/snwtreportenglish.pdf (accessed on 18 December 2014).

28. Lindalen, T. A New House or a New Life? A Case Study of Involuntary Resettlement in the South-North Water Transfer Project in Henan China. Master Thesis, University of Oslo, Oslo, Norway, 2012.

29. Magee, D. Moving the River? China's South-North Water Transfer Project. In Engineering Earth; Brunn, S.D., Ed.; Springer: Dordrecht, The Netherlands, 2011; pp. 1499-1514.

30. South-to-North Water Diversion Project, China. Available online: http://www.water-technology.net/ projects/south_north/ (accessed on 8 December 2014).

31. National Bureau of Statistics of China. China Statistical Yearbook 2013; China Statistics Press: Beijing, China, 2013.

32. Forrester, J.W. Industrial dynamics: A major breakthrough for decision makers. Harv. Bus. Rev. 1958, 36, 37-66.

33. Niazi, A.; Prasher, S.O.; Adamowski, J.; Gleeson, T.P. A system dynamics model to conserve arid region water resources through aquifer storage and recovery in conjunction with a dam. Water 2014, 6, 2300-2321.

34. Winz, I.; Brierley, G.; Trowsdale, S. The use of system dynamics simulation in water resources management. Water Resour. Manag. 2009, 23, 1301-1323.

35. Beall, A.; Fiedler, F.; Boll, J.; Cosens, B. Sustainable water resource management and participatory system dynamics. Case study: Developing the Palouse basin participatory model. Sustainability 2011, 3, 720-742.

36. Liu, C.; Yu, J.; Eloise, K. Groundwater exploitation and its impact on the environment in the North China Plain. Water Int. 2001, 26, 265-272.

37. Pomar, C.; Harris, D.L.; Savoie, P.; Minvielle, F. Computer simulation model of swine production systems: III. A dynamic herd simulation model including reproduction. J. Anim. Sci. 1991, 69, 2822-2836.

38. Ministry of Water Resources. A General Report on Feasibility Study of South-to-North Water Diversion Project; Ministry of Water Resources: Beijing, China, 2005. (In Chinese)

39. Jiangsu Provincial Department of Water Resources. Planning Report on Supporting Projects of South-to-North Water Diversion Project in Jiangsu Province; Jiangsu Provincial Department of Water Resources: Jiangsu, China, 2011. (In Chinese)

40. The Overall Water Quality has Reached the Designed Goals in Eastern and Central Route. Available online: http://news.sohu.com/20141014/n405116497.shtml (accessed on 10 November 2014).

41. People's Daily. Water Quality Compliance Rate Rose from 3\% to $89 \%$ in East Route after 9 Years of Pollution Treatment. Available online: http://paper.people.com.cn/rmrb/html/2012-07/26/ nw.D110000renmrb_20120726_8-02.htm (accessed on 10 November 2014).

42. Hess, T.M.; Knox, J.W. Water savings in irrigated agriculture: A framework for assessing technology and management options to reduce water losses. Outlook Agric. 2013, 42, 85-91.

43. Caliman, F.A.; Robu, B.M.; Smaranda, C.; Pavel, V.L.; Gavrilescu, M. Soil and groundwater cleanup: Benefits and limits of emerging technologies. Clean Technol. Environ. Policy 2011, 13, 241-268.

44. Tang, D.; Yang, Y. Relationship between industrial structure and pollution density: Evidence from recent industrialization in China. Int. J. Ecol. Dev. 2011, 19, 30-43. 
45. National Business Daily. Nansi Lake's Dilemma is to be Solved and the Water Rights are Not Clear. Available online: http://www.nbd.com.cn/articles/2014-08-12/855375.html (accessed on 17 November 2014).

46. Wong, J.L. The Food-Energy-Water nexus: An integrated approach to understanding China's resource challenges. Harv. Asia Quart. 2010, 12, 15-19.

47. Yan, T.; Wang, J.; Huang, J. Urbanization, agricultural water use, and regional and national crop production in China. Ecol. Model. 2015, 2015, doi:10.1016/j.ecolmodel.2014.12.021.

48. Just, R.E.; Netanyahu, S. Conflict and Cooperation on Trans-Boundary Water Resources; Kluwer Academic Publishers: Norwell, MA, USA, 1998.

49. He, S.; Hipel, K.W.; Kilgour, D.M. Water Diversion Conflicts in China: A hierarchical perspective. Water Resour. Manag. 2014, 28, 1823-1837.

50. State Council of China. Announcement on the Assessment Methods for the Most Strict Water Resource Management System. Available online: http://www.mwr.gov.cn/zwzc/zcfg/xzfghfgxwj/ 201301/t20130107_336155.html (accessed on 10 February 2015).

51. Water Resources Department of Jiangsu Province. The Water Resource Planning in Jiangsu Province. Available online: http://www.jswp.gov.cn/WebMain/Main/News.aspx?Id=3109 (accessed on 10 February 2015).

52. Matus, K.J.; Xiao, X.; Zimmerman, J.B. Green chemistry and green engineering in China: Drivers, policies and barriers to innovation. J. Clean. Prod. 2012, 32, 193-203.

53. Bureau of Statistics of Jiangsu. Jiangsu Statistical Yearbook 2014; China Statistics Press: Beijing, China, 2014.

54. Lin, J.Y.; Xu, J. The potential for green growth and structural transformation in China. Oxford Rev. Econ. Policy 2014, 30, 550-568.

55. Moore, S.M. Modernization, authoritarianism, and the environment: The politics of China's South-North Water Transfer Project. Environ. Politics 2014, 23, 1-20.

56. Moore, S. Water Resource Issues, Policy and Politics in China; Brookings Issue Brief. Available online: http://www.brookings.edu/research/papers/2013/02/water-politics-china-moore\#_edn20 (accessed on 13 March 2015).

57. China Daily. Project Set to Deliver Clean Water Next Year. Available online: http://usa.chinadaily.com.cn/china/2012-07/26/content_15618298.htm (accessed on 13 March 2015).

58. Economy, E. The River Runs Black: Environmental Challenge to China's Future; Cornell University Press: Ithaca, NY, USA, 2004.

59. Li, J. The Water Ecological Civilization City Policy Conception and Explore in China; CEWP Scientific Research Cooperation Meeting: Jinan, China, 2013.

60. Benney, J.; Marolt, P. Introduction: Modes of activism and engagement in the Chinese public sphere. Asian Stud. Rev. 2015, 39, 88-99.

61. Magdoff, F. Ecological civilization. Mon. Rev. 2011, 62, 1-25.

62. Yang, H.; Zehnder, A.J. The South-North Water Transfer Project in China: An analysis of water demand uncertainty and environmental objectives in decision making. Water Int. 2005, 30, 339-349.

(C) 2015 by the authors; licensee MDPI, Basel, Switzerland. This article is an open access article distributed under the terms and conditions of the Creative Commons Attribution license (http://creativecommons.org/licenses/by/4.0/). 